\title{
The Significance of Telugu EFL Learners' On the LSRW Method-A Critical Elucidation
}

\author{
P.S. Kiran Kumar \\ Lecturer in English \\ VRS\&YRN College, Chirala, A.P., India
}

\begin{abstract}
Students' learning styles and self-regulated learning strategies are among the main factors that help determine how students learn English language as a foreign language. The aim of this article was to investigate the relationship between EFL learners' perceptual learning style and their self-regulated learning strategies. In this research, the participants will be 50 EFL learners of foreign language institutions classified in upperintermediate level, ranging ages between 19 and 23 years old in Chirala, Prakasam DT, A.P. India. At first, oxford test was given to participants to assure that they are all in the same level of proficiency.
\end{abstract}

The findings of the article revealed there was statistically significant relationship between Telugu learners' perceptual style and self-regulated learning strategies. It revealed the most frequent learning style for Telugu EFL learners was kinesthetic style. And also there is no significant difference between Telugu male and female with regard to main variables. Also, the results of the study show that learners' perceptual learning style preference is given for the Telugu students on the method adopting of LSRW, in order to improve spoken English skills point of view.

However, for my article presentation I have chosen LSRW method for my students in intermediate level who came from Telugu medium back ground of Chirala region of AP, which explores the knowledge of English language for their educational curriculam point of view. I have also found that EFL learning for my students is little bit easy for adopting this method for enriching their proficency in EFL learning for equiping themselves in spoken English.

Keywords: LSRW learning style, self-regulated learning EFL strategies, gender, Telugu.

\section{INTRODUCTION}

In the present era the most important issues in the pedagogical setting are the varied learning styles for acquiring the knowledge of English speaking preferences of the individuals and self-regulated learning strategies in any language learning. Since these two variables are predominant factors which influence the students' success and play a crucial role in the learning process. Therefore teachers and Educators should not ignore it within the field of education.

Learning of English language styles are innate preferences of individuals as to how they prefer to go about the process of learning .Students learn in different ways by seeing and hearing; reflecting and acting; reasoning logically and intuitively; memorizing and visualizing etc. "Learning style," according to Reid "refers to an individual's natural, habitual and preferred way of absorbing, processing and retaining new information.

This research is aimed at investigating the relationship between Telugu EFL learners' learning style and Self-Regulated learning strategies. In the present era one of the most important issues in the learner- centered pedagogical setting is the learning approach of the students which includes the varied learning style preference of the individuals in any language learning. Learning styles are innate preferences of individuals as to how they prefer to go about the process of learning and it is one of the dominant factors which affect the academic success of students. In the process of learning a language particularly a second language, there are many factors including age, gender, motivation, intelligence, anxiety level, context of learning English and learning strategies that determine the academic Success of learners in subject areas not involving second or foreign languages, the use of learning strategies are demonstrably related to achievement. 
The evaluating strategies had an executive function on subscales of cognitive strategies. Selfregulation is given little emphasis in the university curriculum in Iran. Generally, the emphasis on English teaching in universities in Iran is on the four language skills. Personality factors that related to autonomy and self -regulation directly is not paid attention to the rural back ground students of Chirala of A.P. India, as a significant factor in language learning I,e for Telugu back ground students of intermediate level.

\section{SigNIFICANCE OF THE RESEARCH}

This study is different from the studies done so far based on the following points. First, Few studies tried to investigate these two variables self- regulation and learning styles- simultaneously. Most researchers studied them separately in different research projects. Second, most of the students are the rural back ground on whom I researched the relationship between skills (listening, reading, writing, speaking) learning strategies and learning styles specially for Telugu medium back ground. Few students tried to investigate the relationship between self- regulation and learning EFL styles simultaneously. Moreover having information about learning styles of the learners will help learners and teachers to match learning and teaching style and achieve optimum outcome.

1. To explore the relationship between learning style and self-regulated strategies of Telugu EFL learners.

2. To explore the difference between Telugu male and female with regard to their self-regulated strategies.

3. To identify Telugu EFL learners' learning style preferences for high and low self-regulated learners.

\section{RESEARCH QUESTIONS AND HyPOTHESES OF EFL OF TELUGU MEDIUM PUPIL}

Bearing in mind the problem expounded on so far, this study set out to provide plausible answers to the following questions:

1. Is there any significant relationship between Telugu and English EFL learners' learning style and their self- regulated strategies?

2. Is there any significant difference between Telugu male and female with regard to their selfregulated strategies?

3. What are the learning style preferences for high and low self- regulated learners?

To investigate the above mentioned research questions, the following hypotheses are formulated:

1. There is no significant relationship between Telugu EFL learners' Learning style and their selfregulated learning strategies.

2. There is no significant difference between Telugu male and female with regard to their selfregulated strategies.

In this study, the participants will be 50 EFL learners of rural back ground students for foreign language institutions classified in a pre-intermediate level and upper- intermediate, ranging ages between 19 and 23 years old in Chirala A.P. India. They will be consisting of both20 males and 30 females. They will be select randomly. At first, oxford test was given to participants to assure that they are all in the same level of proficiency.

For the purpose of the present study, a number of instruments were prepared which will be described in order:

\section{EFL LEARNING STYLE METHOD}

The 30 item EFL was adapted and used to identify participants, perceptual learning style preferences. The EFL examines four perceptual and two social (group and individual) learning style preferences. The questionnaire consists of two parts. The first part was designed by the author to identify participants' demographic information such as gender, age, fields of study, English grade, and length of English education. The second part comprised 30 items of learning strategy statements classified into 6 categories: Auditory Learning, Visual Learning, Tactile Learning, Kinesthetic Learning, Group Learning, and Individual Learning. Each category provides information on how individuals prefer to 
learn a language. The type of response scale is based on the Likert scale containing five items with regard to the degree of agreement or disagreement. That is, the participants were asked to indicate: (1) strongly agree; (2) agree; (3) neutral; (4) disagree; and (5) strongly disagree. The questionnaire was piloted prior to the actual data collection and the reliability Cronbach's Alpha was obtained at 0.873 .

The EFL Learning Style Preference Questionnaire developed by Telugu medium back ground students and the questionnaire was validated through pilot testing and their proficiency reliability of the questionnaire was found to be 0.72 .

\section{RESULTS}

In this study the data was collected that the number of Telugu medium students who were more benefited by this method.

The statistical analyses were conducted by using the Statistical Package for EFL Learning, Speaking, Reading and writing method for EFL point of view (LSRW) specially more benefited by the rural back ground Telugu medium students. And those Telugu back ground students who could learn this method may definitely stand on their own legs in their futur.

\section{CONCLusion}

The purpose of the study was to investigate whether there is statistically significant relationship between Telugu and English EFL learners' perceptual learning style and their Self-Regulated learning strategies. And also this study to identify whether there is significant difference between Telugu male and female with regard to their self- regulated strategies and whether there is significant difference between Telugu male and female with regard to their perceptual learning style. In addition to, it should identify Telugu EFL learners' perceptual learning style preferences for high and low selfregulated learners. The findings revealed that there is statistically significant relationship between Telugu EFL learners' perceptual learning style and their Self-Regulated learning strategies. Also, it revealed the most frequent learning style for Telugu EFL learners at this proficiency level was kinesthetic style. Tactile and auditory styles ranked the second and third styles. Also it was shown that individual style was the least frequent. Among language learning strategies, intrinsic value and selfefficacy strategies were mostly used by Telugu EFL learners, while test anxiety strategies were the least used strategy for rural back ground students of Chiral, AP, India.

\section{REFERENCES}

Oxford, R. L. (1999). Style wars' as a source of anxiety in language classrooms. In D. J. Young (Ed.), Affect in foreign language and second language learning (pp. 216-237).Boston: MacGraw-Hill.

Oxford, R. L. (1995). Gender differences in learning styles: What do they mean? In J. M. Reid (ed.), Learning styles in the ESL/EFL classroom (pp. 34-46). Boston: Heinle\&Heinle.

Reid, J.M. (1995). Learning styles in the ESL/EFL classroom. Boston: Heinle\&Heinle.

Reid, J.M. (1987). The learning style preferences of ESL students. TESOL Quarterly, 21, 1, 87-111.

Rossi-Le, L. (1995). Learning styles and strategies in adult immigrant ESLa students. In J.M. Reid (Ed.), Learning styles in the ESL/EFL classroom (pp. 119-125). Boston: Heinle\&Heinle.

Sadeghy, A. R., \&Mansouri, A. (2014).THE RELATIONSHIP BETWEEN LEARNERS' GOALORIENTED AND SELF-REGULATED LEARNING AND THEIR ENDORSEMENT OF L2 LEARNING STRATEGIES. International Journal of Language Learning and Applied Linguistics World (IJLLALW), Volume 5 (2), 574-593.

Scarcella, R. \& Oxford, R., (1992). The Tapestry of Language Learning: The Individual in the Communicative Classroom. Boston: Heinle \&Heinle.

Sparks, R. \&Ganschow, L. (1995).Searching for the Cognitive Locus of Foreign Language Learning Difficulties: Linking First and Second Language Learning. Modern Language Journal, 77, 289302.

Stebbins, C. (1995). Culture-specific perceptual-learning style preferences of postsecondary students of English as a second language. In: Reid, J. (Ed.), Learning Styles in the ESL/EFL Classroom. Heinle and Heinle, Boston, MA. 


\section{AUTHOR'S BIOGRAPHY}

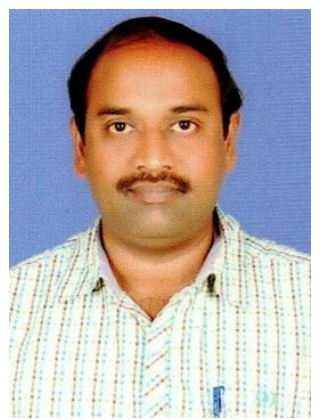

P.S. Kiran Kumar, who has been working as lecturer in English in VRS \& YRN college, Chirala, Prakasam (dist), Andhra Pradesh, India. At present, he is pursuing his phd in Aacharya Nagarjuna University Guntur, Andhra Pradesh, india. He has participated in national and international English conferences. He has presented several scholarly articles at various national and international conferences. 